\title{
Changes in gene expression of Prymnesium parvum induced by nitrogen and phosphorus limitation
}

\author{
Zhenfeng Liu ${ }^{\dagger}$, Amy E. Koid ${ }^{\dagger}$, Ramon Terrado, Victoria Campbell, David A. Caron and \\ Karla B. Heidelberg *
}

Department of Biological Sciences, University of Southern California, Los Angeles, CA, USA

OPEN ACCESS

Edited by:

Senjie Lin,

University of Connecticut, USA

Reviewed by:

LeAnn Whitney,

University of Rhode Island, USA

Yunyun Zhuang,

Ocean University of China, China

*Correspondence:

Karla B. Heidelberg,

Department of Biological Sciences,

University of Southern California, 3616

Trousdale, Parkway, AHF 107,

Los Angeles, CA 90089, USA

kheidelb@usc.edu

${ }^{\dagger}$ These authors have contributed equally to this work.

Specialty section:

This article was submitted to

Aquatic Microbiology,

a section of the journal

Frontiers in Microbiology

Received: 18 February 2015

Accepted: 10 June 2015

Published: 24 June 2015

Citation:

Liu Z, Koid AE, Terrado R, Campbell V, Caron DA and Heidelberg KB (2015)

Changes in gene expression of

Prymnesium parvum induced by

nitrogen and phosphorus limitation.

Front. Microbiol. 6:631.

doi: 10.3389/fmicb.2015.00631
Prymnesium parvum is a globally distributed prymnesiophyte alga commonly found in brackish water marine ecosystems and lakes. It possesses a suite of toxins with ichthyotoxic, cytotoxic and hemolytic effects which, along with its mixotrophic nutritional capabilities, allows it to form massive Ecosystem Disruptive Algal Blooms (EDABs). While blooms of high abundance coincide with high levels of nitrogen $(N)$ and phosphorus $(P)$, reports of field and laboratory studies have noted that $P$. parvum toxicity appears to be augmented at high $\mathrm{N}: \mathrm{P}$ ratios or P-limiting conditions. Here we present the results of a comparative analysis of $P$. parvum RNA-Seq transcriptomes under nutrient replete conditions, and $\mathrm{N}$ or $\mathrm{P}$ deficiency to understand how this organism responds at the transcriptional level to varying nutrient conditions. In nutrient limited conditions we found diverse transcriptional responses for genes involved in nutrient uptake, protein synthesis and degradation, photosynthesis, and toxin production. As anticipated, when either $\mathrm{N}$ or $\mathrm{P}$ was limiting, transcription levels of genes encoding transporters for the respective nutrient were higher than those under replete condition. Ribosomal and lysosomal protein genes were expressed at higher levels under either nutrient-limited condition compared to the replete condition. Photosynthesis genes and polyketide synthase genes were more highly expressed under $\mathrm{P}$-limitation but not under $\mathrm{N}$-limitation. These results highlight the ability of $P$. parvum to mount a coordinated and varied cellular and physiological response to nutrient limitation. Results also provide potential marker genes for further evaluating the physiological response and toxin production of $P$. parvum populations during bloom formation or to changing environmental conditions.

Keywords: Prymnesium parvum, nutrient limitation, gene expression, polyketide synthase, algal bloom

\section{Introduction}

Prymnesium parvum is a unicellular prymnesiophyte (haptophyte) alga that is found predominantly in brackish waters and lakes, as well as in some coastal marine ecosystems (Moestrup, 1994; Edvardsen and Paasche, 1998). Like all microbial eukaryotes, P. parvum requires nitrogen $(\mathrm{N})$ and phosphorus $(\mathrm{P})$ for basic physiological processes, but it is able to grow and bloom in a wide range of $\mathrm{N}$ and $\mathrm{P}$ concentrations. P. parvum is considered a model IIA mixotroph (Stoecker, 1998; Sanders, 2011), an alga that is primarily photosynthetic but one that can also use phagotrophy to supply essential substances needed for growth. Mixotrophic protists of this type are widespread in both freshwater and marine systems and can account for up to $50 \%$ of the 
bacterivory in some systems and also contribute to predation on other microbial taxa (Stoecker, 1998; Burkholder et al., 2008; Mitra and Flynn, 2010). The ability to ingest other organisms or take up dissolved organic matter is hypothesized to provide a competitive advantage for mixotrophic algae such as $P$. parvum when essential nutrients such as $\mathrm{N}$ and $\mathrm{P}$, as well as iron, vitamins and other trace elements are limiting in the environment.

$P$. parvum can produce an array of toxins with hemolytic, cytotoxic, ichthyotoxic and possibly neurotoxic activities, at least some of which function in the acquisition of prey (Yariv and Hestrin, 1961; Shilo, 1971, 1981; Tillmann, 2003; Cichewicz and Hambright, 2010; Manning and La Claire, 2010). However, toxins produced by the alga likely constitute a suite of compounds with diverse cellular origins and biological activities (Manning and La Claire, 2010), of which only two have been isolated; prymnesin1 and prymnesin-2 (Igarashi et al., 1999). The configuration of these cyclic polyethers have led researchers to postulate that, like the dinoflagellate toxins brevitoxin and okadaic acid, the synthesis of these molecules might involve polyketide synthase genes (Manning and La Claire, 2010; Freitag et al., 2011; Manning and La Claire, 2013).

Recurrent Ecosystem Disruptive Algal Blooms (EDABs) formed by $P$. parvum have resulted in significant economic losses in the aquaculture industry (Moestrup, 1994; Edvardsen and Paasche, 1998; Sunda et al., 2006), and these events appear to be increasing in frequency and geographical range. In recent years, $P$. parvum has spread throughout the northeast coast of the United States and into southwestern states, most notably Texas and Oklahoma (Aguiar and Kugrens, 2000; Watson, 2001; Hargraves and Maranda, 2002; Baker et al., 2009; Hambright et al., 2010). Blooms of P. parvum sufficient to result in fish kills tend to occur in environments characterized by high levels of macronutrients (Lindholm et al., 1999; Graneli and Salomon, 2010). Laboratory studies have indicated that P. parvum may produce toxins constitutively, but also that toxicity appears to increase under conditions of $\mathrm{N}$ - or P-limitation (Graneli and Johansson, 2003; Uronen et al., 2005; Graneli and Salomon, 2010). In accordance with those lab findings, toxicity in natural environments has been observed to be highest under high N:P ratios (Kaartvedt et al., 1991; Aure and Rey, 1992; Lindholm et al., 1999). These observations imply that highly toxic blooms of $P$. parvum capable of producing fish kills might occur where overall nutrient availability is sufficient to allow the alga to bloom but then subsequent conditions result in growth limitation that results in increased toxin production per cell.

Transcriptomic analysis provides an opportunity to probe the molecular underpinnings of the function and ecology of protists whose large genomes currently present financial and bioinformatics challenges for sequencing and assembly (McGettigan, 2013). Changes in gene expression of ecologically important species have been studied using methods such as expressed sequence tag (EST), microarray libraries or tagbased sequencing such as long-serial analysis of gene expression (long-SAGE) (von Dassow et al., 2009; Moustafa et al., 2010; Park et al., 2010; Wurch et al., 2011). Recently, higher throughput RNA-seq has become a common technology for gene expression analyses. These approaches allow for comparative analysis of differential gene expression, which can provide information into the physiological or cellular processes of protists whose large and complex genomes have not yet been sequenced.

Such studies have begun to provide insight into the transcriptional response of $P$. parvum to environmental conditions thought to affect its activities in natural communities. For example, one early study of a $P$. parvum EST library revealed the presence of phosphate transporter genes and genes that might be involved in polyketide synthesis (La Claire, 2006). A subsequent study using a combination of EST libraries and microarrays described differential expression of genes under $\mathrm{N}$ - and $\mathrm{P}$ - limitation, showing a strong response in P-limited cells by upregulating genes involved in the uptake of $\mathrm{P}$ (Beszteri et al., 2012). More recently, an RNA-Seq study focused on the mixotrophic nutrition of this alga, showing that different genes and pathways were upregulated depending on whether $P$. parvum was grown in the presence of bacteria or ciliates as prey (Liu et al., 2015). At a somewhat broader phylogenetic scale, comparative RNA-Seq transcriptome analysis described the differences between functional gene categories of four species of prymnesiophyte algae including $P$. parvum, and examined gene expression among phototrophic, heterotrophic and mixotrophic species of protists (Koid et al., 2014).

The present study investigated and compared specific changes in P. parvum gene expression under $\mathrm{N}$ - and P-limitation using RNA-Seq. Although this topic has been previously visited by Beszteri et al. (2012), advances in RNA-Seq technology used in this study offers improvement in both coverage of the transcriptome and resolution of gene expression levels. We explored how nutrient limitation impacts gene expression with an emphasis on the genes responding uniquely to $\mathrm{N}$ and $\mathrm{P}$ limitation relative to the alga growing in nutrient replete medium. Our results indicate that the expression levels of transporters for $\mathrm{N}$ and $\mathrm{P}$ were higher when the respective nutrient was limiting and that ribosomal and lysosomal proteins were more highly expressed when either $\mathrm{N}$ or $\mathrm{P}$ was limiting. In addition, photosynthesis genes were more highly expressed under P-limitation but not under N-limitation. Polyketide synthase genes were also more highly expressed under P-limitation, and may be related to the acquisition of extracellular P.

\section{Methods}

\section{Culture Conditions and RNA Isolation}

Prymnesium parvum UOBS-LP0109 (clone Texoma1) was isolated from Lake Texoma, Oklahoma, USA, by K. David Hambright, University of Oklahoma, transferred to the University of Southern California and made clonal and axenic by micropipetting single cells through rinses of sterile medium. The nutrient replete culture was grown in $2 \mathrm{~L}$ volumes in $2.8 \mathrm{~L} \mathrm{ml}$ Pyrex glass Fernbach flasks under specified conditions (Table 1). Nutrient-limited cultures were obtained by acclimation from the axenic replete culture and were prepared by at least three, 10$20 \%$ sequential inoculations at approximately 2 -week intervals from the axenic replete culture.

The replete treatment was harvested during mid-exponential growth phase, while the nutrient-limited treatments were 
TABLE 1 | Culture conditions for Prymnesium parvum.

\begin{tabular}{|c|c|c|c|c|c|}
\hline Culture & Media & Nutrients & Temp & L:D cycle & Irradiance ${ }^{\mathbb{I}}$ \\
\hline 1 & $\mathrm{~L}_{1}^{\dagger}$, -silica, 18ppt* & $\begin{array}{l}882 \mu \mathrm{M} \mathrm{NO}_{3}^{-} \\
36.2 \mu \mathrm{M} \mathrm{PO}_{4}^{-3}\end{array}$ & $18^{\circ} \mathrm{C}$ & $12: 12$ & $300 \mu \mathrm{E} \mathrm{m}^{-2} \mathrm{~s}^{-1}$ \\
\hline 2 & L1, -silica, N/100,18ppt & $8.82 \mu \mathrm{M} \mathrm{NO}_{3}^{-}$ & $18^{\circ} \mathrm{C}$ & $12: 12$ & $300 \mu \mathrm{E} \mathrm{m}^{-2} \mathrm{~s}^{-1}$ \\
\hline 3 & L1, -silica, P/100, 18ppt & $0.362 \mu \mathrm{M} \mathrm{PO}_{4}^{-3}$ & $18^{\circ} \mathrm{C}$ & $12: 12$ & $300 \mu \mathrm{E} \mathrm{m}^{-2} \mathrm{~s}^{-1}$ \\
\hline
\end{tabular}

† Guillard and Hargraves (1993) or https://ncma.bigelow.org.

"Salinity is indicated as parts per thousand (ppt).

I/Ilumination was provided by Philips F20T12CW bulbs and measured using a QSL-100 sensor with QSP-170 deckbox (Biospherical Instruments, Inc.).

harvested during stationary phase. RNA was isolated from the $P$. parvum cultures as described previously (Koid et al., 2014). Briefly, cultures were spun down, and the supernatant was decanted. The pellet was dissolved in TRI reagent (Ambion), and RNA was extracted from the homogenates using the Ribopure kit (Ambion). The eluted RNA was treated with DNase (Sigma) and cleaned and concentrated. The RNA was quantified using a Qubit 2.0 Fluorometer (Invitrogen) and run on an E-gel iBase with E-gel Gel EX 1\% (Invitrogen) to check for nucleic acid quality.

\section{Library Preparation and Sequencing}

RNA quality was assessed using the Agilent 2100 Bioanalyzer. Libraries were made using a previously published protocol (Koid et al., 2014). Briefly, Illumina's TruSeq RNA Sample Preparation Kit was used with $2 \mu \mathrm{g}$ of RNA. The average insert size of each library ranged from 250 to $350 \mathrm{bp}$. Libraries were sequenced on an Illumina HiSeq 2000 to obtain $2 \times 50$ bp (pairedend) reads. Over $2 \mathrm{Gbp}$ of sequence was generated per library. Library preparation and sequencing were performed as part of the Marine Microbial Eukaryote Transcriptome Sequencing Project (MMETSP) supported by the Gordon and Betty Moore Foundation (Keeling et al., 2014). The original sequence data are publicly available from NCBI Sequence Read Archive under accession number SRA166613 and sample IDs MMETSP0006_2, MMETSP0007, and MMETSP0814, for axenic, P-limited and $\mathrm{N}$-limited treatment, respectively.

\section{Transcriptome Assembly}

Bioinformatic analysis procedures were adapted and developed from guidelines established by the MMETSP (Keeling et al., 2014). Sequences of all treatments were first checked for quality using the FASTX toolkit (http://hannonlab.cshl.edu/ fastx_toolkit/index.html) with options “-p 80 -q 20" (at least $80 \%$ positions with quality score of at least 20 ). All remaining sequences were combined and assembled de novo using a combination of a de Brujin graph and overlap-based algorithms. Sequences were first assembled using ABySS v. 1.3.2 (Simpson et al., 2009) at four different k-mer settings of 19, 25, 31, and 37. The resulting four assemblies were merged using Trans-ABySS v. 1.4.4 (Robertson et al., 2010). Redundant contigs were removed using CD-Hit-EST v. 4.5.7 (Li and Godzik, 2006). The remaining contigs were then further assembled using CAP3 (Huang and Madan, 1999) with options “-p 99 -o 50 -k 0” (at least 50 bp overlap with $99 \%$ identity and no end clipping). Scaffolding of the resulting contigs was inferred using ABySS (Simpson et al., 2009). The GapCloser v. 1.12 application of the SOAPdenovo
(Luo et al., 2012) was employed to fill in gaps in the assembly. Scaffolds were broken into contigs where gaps remained unfilled. Contigs shorter than 150 bp were discarded. CD-Hit-EST was used again to remove redundant contigs. Lastly, the contigs were searched against SILVA database (Quast et al., 2013) using BLAST (Altschul et al., 1990) to identify and remove rRNA sequences. Assemblies are available in the Supplementary Information or from the corresponding author.

\section{Transcriptome Annotation}

Protein-coding genes longer than $150 \mathrm{bp}$ were predicted from the assembled transcriptome using ESTscan (Iseli et al., 1999). Genes were annotated at the $1 \mathrm{e}-5$ level based on a variety of database searches including HMMER3 v. 3.1b1 (Zhang and Wood, 2003) searches against Pfam (Finn et al., 2010) and Tigrfam (Haft et al., 2001) databases and BLAST search against NCBI nr database. KEGG orthology and Gene Ontology terms were obtained using the KEGG annotation server (Moriya et al., 2007) and BLAST2GO (Conesa et al., 2005). Genes were annotated based on their homology to Pfam or Tigrfam protein families, KEGG or GO annotations, or best hit in $\mathrm{nr}$ database, in that order. Finally, automated annotation of selected genes in our datasets were manually inspected and curated.

\section{Differentially Expressed Genes}

Sequences of all three datasets were aligned to the annotated genes of the assembled transcriptome using BWA ( $\mathrm{Li}$ and Durbin, 2009). Read pairs that aligned to genes correctly were counted. Only read pairs mapped uniquely to genes were considered. Normalization and statistical analyses of the read counts of each gene were carried out in edgeR (Robinson et al., 2010). Pairwise comparisons between all three pairs of treatments were carried out using the "exact test" function in edgeR with dispersion set at $0.1 . P$-values were adjusted to false discovery rate using p.adjust in $\mathrm{R}$ (Benjamini and Hochberg, 1995). Only genes with adjusted $p<0.05$ were accepted as having significantly different expression levels between different treatments. Read counts of 0 were replaced by 1 when calculating FPKM (fragments per kb per million fragments mapped) to avoid division by zero when calculating fold changes of gene expression between treatments. Genes whose FPKM values were below 1 in all treatments were ignored.

\section{Polyketide Synthase Analysis}

Putative polyketide synthase (PKS) genes were identified by the automated annotation pipeline, and a local BLAST 
search against Emiliania huxleyi polyketide synthase sequences obtained from GenBank. The NRPS-PKS tool (Bachmann and Ravel, 2009) was used to identify the PKS domains present.

\section{Caveats and Limitations of the Study}

We realize that transcriptome data in this study lacked replication. Therefore, we were purposely careful when interpreting the data. For example, inferences were made based on the expression patterns of a group of genes involved in the same function, never based on the expression pattern of a single gene. $\mathrm{N}$-limited and P-limited treatments in this study were obtained by growing batch cultures of $P$. parvum to the stationary growth phase. Therefore, gene expression of these nutrient-limited cultures may have included responses that were a consequence of generalized stress, or changes related to life cycle processes associated with entering the stationary growth phase. However, gene expression observed for $\mathrm{N}$ - and P-limited treatments indicated several different responses to these nutrients, implying that transcriptomic responses of the alga were not overwhelmingly related to generalized stress or life cycle events associated with the stationary growth phase (which would presumably have been similar for the two nutrient-limited treatments).

\section{Results}

\section{General Transcriptome Characteristics}

Individual transcriptome characteristics are shown in Table 2. The assembled $P$. parvum transcriptome of the combined replete, $\mathrm{N}$-limited and P-limited treatments contained 51,580 contigs and 42,862 genes for a total assembled transcriptome size of $43.95 \mathrm{Mbp}$. The number of putative protein-coding genes was comparable to other transcriptomes in the Gordon and Betty Moore Foundation MMETSP database and to the number of predicted genes in Emiliania huxleyi, another prymnesiophyte alga (Read et al., 2013). All necessary genes involved in glycolysis/gluconeogenesis, the TCA cycle, biosynthesis of amino acids, and nitrogen metabolism were present in the assembled transcriptome, indicating adequate sequencing depth to cover most actively transcribed genes.

\section{Differentially Expressed Genes}

Approximately 25\% $(10,459)$ of the genes in our assembled transcriptome were differentially expressed in at least one pair of treatments. When clustered by their transcription patterns across three treatments, six different clusters of genes emerged. Plimitation seemed to have the largest impact on the transcriptome in terms of the numbers of differentially expressed genes. 3114 genes (cluster 3 in Figure 1) and 3373 genes (cluster 4) had highest and lowest expression levels in P-limited treatment, respectively. On the other hand, only 861 genes (cluster 1) and 522 genes (cluster 6) had highest and lowest expression levels in N-limited treatment. 1200 genes (cluster 2) were more highly expressed in both nutrient limited treatments, and 1389 genes (cluster 5) were most highly expressed in the replete treatment.
TABLE 2 | Summary of $P$. parvum transcriptomes and assembly.

\begin{tabular}{|c|c|c|c|}
\hline & Replete & P-limited & N-limited \\
\hline No. of read pairs* & $19,277,859$ & $18,785,652$ & $11,404,203$ \\
\hline Assembly statistics & \multicolumn{3}{|c|}{$\begin{array}{l}51,580 \text { contigs; } 43.95 \mathrm{Mbp} \text {; N50 = } 1276 \mathrm{bp} ; \\
\text { 42,862 predicted genes, } 32.97 \mathrm{Mbp}\end{array}$} \\
\hline Reads mapped back to assembly & $76.7 \%$ & $55.5 \%$ & $76.9 \%$ \\
\hline Reads mapped back to genes & $48.4 \%$ & $22.8 \%$ & $49.1 \%$ \\
\hline
\end{tabular}

*After quality filtering.

\section{Nitrogen Uptake, Transport, and Assimilation}

Under N-limitation, changes in relative expression levels were observed for many genes related to $\mathrm{N}$-uptake, transport and assimilation (Figure 2). Genes coding for proteins involved in nitrogen uptake, including nitrate reductase (NR), nitrite reductase (NiR), glutamine synthetase (GS) and glutamate synthase (GOGAT), had overall higher expression levels $(p<$ $0.05)$ in the $\mathrm{N}$-limited condition compared to the replete (Figures 3A,D). There were three isoforms of GS in our dataset. Two were annotated as glutamine synthetase III (GSIII) and most likely cytosolic isoforms. The third presented a signal peptide indicating a chloroplastidic localization, thus most likely being a putative glutamine synthetase II (GSII). One of the GSIII genes showed a marked response under $\mathrm{N}$-limitation, being expressed at much higher level than that in the replete treatment. The other two GS genes and two GOGAT genes were not differentially expressed between the $\mathrm{N}$-limited treatment and the replete treatment. Overall, expression levels of the nitrogen assimilation genes under P-limitation were not significantly different than those in the replete treatment (Figure 3D).

In addition to nitrogen metabolism genes, we found 20 putative inorganic nitrogen transporter genes: eight ammonium transporters, one nitrate transporter, and genes annotated as formate/nitrite transporters. The ammonium transporters and the nitrate transporter had higher expression levels $(p<0.01$, $t$-test) under $\mathrm{N}$-limitation compared to the replete condition but lower relative expression levels in the P-limited condition $(p<0.05$, Figures 3A,B). In contrast, genes annotated as formate/nitrite transporters did not show the same pattern of regulation and presented a lower expression level in both $\mathrm{N}$ and P-limited compared to the replete treatment $(p<0.001$, Figure 3C). Two single copy urea transporters were detected in the transcriptome. The first was a urea permease of the UT family that appeared to be targeted to mitochondria and was not expressed differently in any treatment. The second was an active urea transporter (DUR3) with a higher relative expression level in the $\mathrm{N}$-limited treatment compared to the replete treatment (Figure 3A, Table S1).

\section{Other Nitrogen Metabolism Genes}

Three different transporters for purines were expressed, possibly with affinities for different substrates (Supplemental Figure 1). Two of those were not differentially expressed among treatments, but one of the most highly expressed genes in the $\mathrm{N}$-limited 


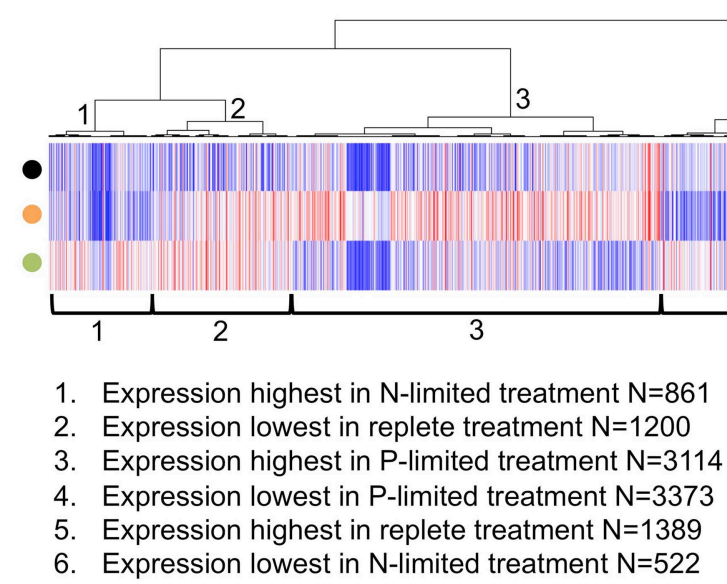

expression patterns. When calculating Pearson correlation values, FPKM

FIGURE 1 | Heatmap of expression levels (in the form of FPKM values) of all differentially expressed genes (between at least one pair of treatments) in three treatments. Each thin column represents a single gene and its expression level in three treatments, Genes were arranged by hierarchical clustering (1-Pearson correlation, average linkage) of their values smaller than zero were transformed to zero to reduce the impact of sub-zero FPKM values because they were mostly derived from very small read counts which have virtually no statistical significance. FPKM is the fragments per kilobase per million fragments mapped. treatment corresponded to one of the purine transporters, a xanthine uracil permease (XUV); the expression level of this gene was higher in the $\mathrm{N}$-limited treatment relative to the replete treatment (Table 3). A xanthine dehydrogenase that catalyzes the conversion of xanthine to urate (or uric acid) also showed a higher relative expression level in the $\mathrm{N}$-limited treatment compared to the replete (Table 3 ).

Genes related to the biosynthesis of purines also had higher relative expression levels in the $\mathrm{N}$-limited treatment compared to the replete treatment, including the whole pathway converting ribose-5-phosphate to inosine monophosphate (IMP) and then interconverting IMP to xanthine monophosphate (XMP), guanine monophosphate (GMP), and adenosine monophosphate (AMP). Four of these genes, purL, purM, purB, and $p u r H$, were expressed at levels higher in the $\mathrm{N}$-limited treatment compared to the replete treatment.

We detected a transcript coding for a copper amine oxidase $(\mathrm{CuAO})$ with expression levels lower under P-limitation compared to the replete treatment (Table 3). The translated protein presents an $\alpha$-helix at the $\mathrm{N}$-terminal, suggesting that it corresponds to a membrane-bound $\mathrm{CuAO}$ (Figure 2). This gene was not differentially expressed under $\mathrm{N}$-limitation.

There were also differences in expression levels of genes involved in intracellular nitrogen processing. Two types of carbamoyl phosphate synthase (CPS) genes were present in the combined transcriptome, previously designated in diatoms as unCPS and pgCPS (Allen et al., 2011). The former is localized to the mitochondria and is involved in the urea cycle, using ammonium as a substrate, while the latter is likely cytosolic and uses glutamine as a substrate in the first committed step of pyrimidine synthesis (Allen et al., 2011). There were six copies of pgCPS in the transcriptome, three of which were not differentially expressed in any of the treatments. The other three were not differentially expressed under $\mathrm{N}$-limitation but had relatively lower expression under P-limitation (Figure 3A). Both unCPS genes found in the transcriptomes had lower transcription levels in the P-limited treatment, but neither were differentially expressed under $\mathrm{N}$-limitation.

Two other genes involved in the urea cycle, argininosuccinate synthase and argininosuccinate lyase, also had higher expression levels under $\mathrm{N}$-limitation (Table 3). Under P-limitation, argininosuccinate synthase was not differentially expressed while argininosuccinate lyase had a slightly lower expression level compared to the replete treatment (Table 3). The other urea cycle genes, arginine, and ornithine transcarbamoyltransferase were not differentially expressed among the three treatments.

\section{Phosphate Transporters}

Overall, expression levels of phosphate transporters were higher in the P-limited treatment, but were not statistically different in the $\mathrm{N}$-limited treatment, compared to the replete treatment (Figure 3E). The most highly expressed gene in the P-limited treatment was one of two genes that were annotated as putative pho4 family genes, a high-affinity sodium-phosphate transporter family that is generally regulated by phosphorous starvation in fungi (Dick et al., 2014) (Supplemental Figure 2). The expression level of this gene was higher in the P-limited treatment compared to the replete treatment. The second pho4 gene was not differentially expressed. Three other putative sodiumdependent inorganic phosphate transporters most related to the Solute Carrier family (SLC) were more highly expressed in the P-limited condition, while another one annotated as a sodium-dependent inorganic phosphate transporter of the Major Facilitator Superfamily (MFS) was not differentially expressed.

\section{Photosynthesis Proteins}

Photosynthesis-related proteins found in the $P$. parvum transcriptome consisted of chlorophyll A-B binding proteins and light-harvesting proteins. Most photosynthesis-related genes are 


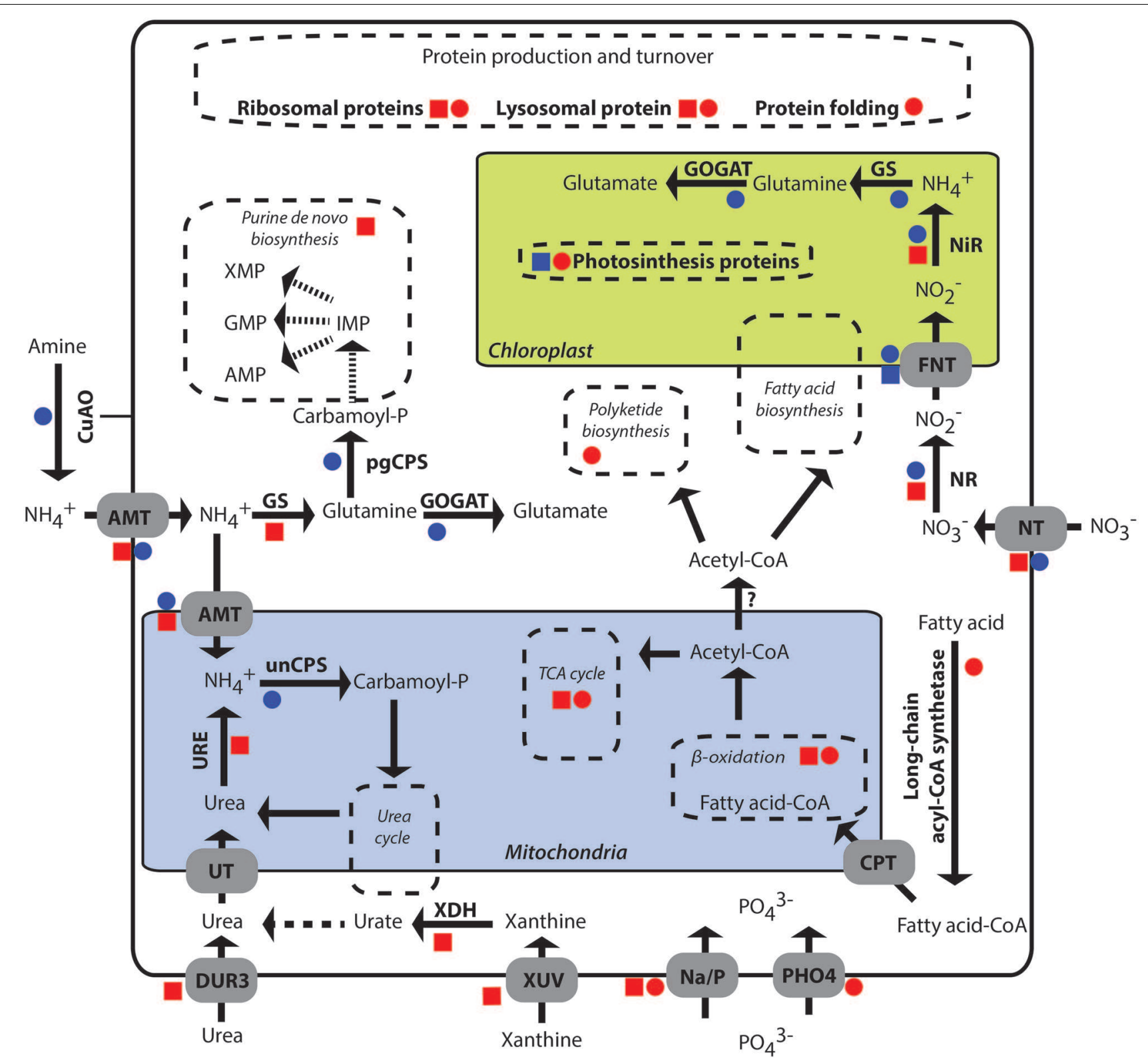

N limited

Plimited
Higher relative expression

Lower relative expression
Transporter
Reaction
FIGURE 2 | Overview of differentially expressed pathways and genes of $\boldsymbol{P}$. parvum grown to $\mathbf{N}$ - or $\mathbf{P}$-limitation, relative to nutrient replete cultures. Squares indicate response under

$\mathrm{N}$-limitation compared to the replete condition, while circles indicate response under P-limitation compared to the replete condition. Red and blue indicate up- and down-regulation respectively. AMT, ammonium transporter; CPT, carnithine palmitoyl transferase; CuAO, Copper amine oxidase; DUR3 and UT, urea transporter; FNT, formate/nitrite transporter; GOGAT, glutamate synthase; GS, glutamine synthetase; $\mathrm{Na} / \mathrm{P}$, sodium-dependent inorganic phosphate transporter; $\mathrm{NiR}$, nitrite reductase; NR, nitrate reductase; NT, nitrate transporter; pgCPS, carbamoyl phosphate synthase (involved in pyrimidine syntheses, uses glutamine as substrate); $\mathrm{PHO} 4$, phosphate transporter of the pho4 family; unCPS, carbamoyl phosphate synthase (involved in the urea cycle, uses ammonium as substrate); URE, urease; $\mathrm{XDH}$, xanthine dehydrogenase; XUV, xanthine-uracil permease. encoded in the chloroplast genome, and thus were not recovered in our datasets due to the poly-A+ enrichment technique used.
We found 38 chlorophyll A-B binding protein genes that were differentially expressed among the treatments. Most of these genes had lowest expression levels in the $\mathrm{N}$-limited treatment 


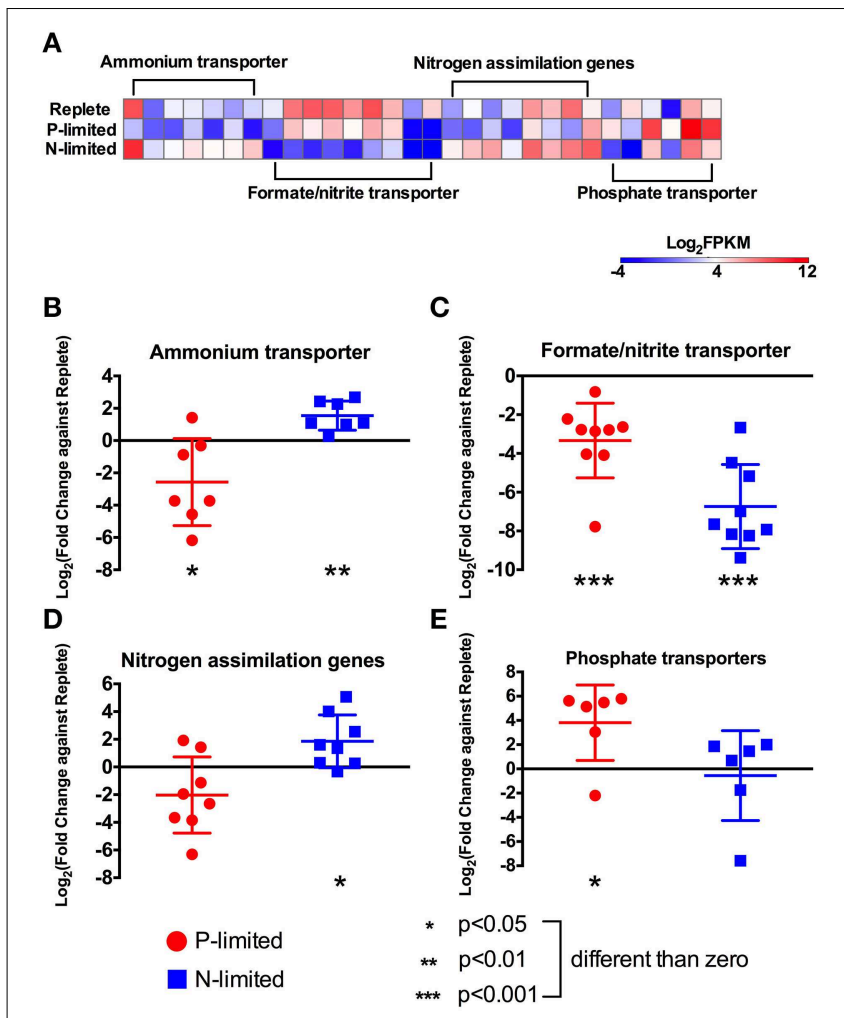

FIGURE 3 | Expression levels and fold changes of nitrogen and phosphorus metabolism genes. (A) Heatmap of all differentially expressed genes involved in nitrogen and phosphorus metabolism. Log $_{2}$ (fold change against replete treatment) in both $\mathrm{P}$-limited and $\mathrm{N}$-limited treatments were plotted for genes encoding ammonium transporters (B), formate/nitrite transporters (C), nitrogen assimilation genes (D), and phosphate transporters (E). For each category, a dot represents a single gene; the bar represents mean $\pm \mathrm{SD}$ of the $\mathrm{Log}_{2}$ fold changes. For each category and each treatment, $t$-tests were used to test whether the $\log _{2}$ fold change values were significantly different from 0 , i.e., whether these genes were differentially expressed compared to the replete treatment, collectively. Different $p$-values are represented by different numbers of stars. For a list of these genes and their read counts and FPKM values, see Table S1.

(Figure 4A). Overall, these genes had higher expression levels under P-limitation $(p<0.01)$, and lower expression levels under $\mathrm{N}$-limitation $(p<0.001)$, compared to the replete treatment (Figure 4B).

Relative expression levels of genes coding for light-harvesting proteins also exhibited opposite patterns under $\mathrm{P}$ - and $\mathrm{N}$ limitation. That is, transcription levels of these genes were generally higher in the P-limited treatment $(p<0.05)$, but were lower in the $\mathrm{N}$-limited treatment relative to the replete treatment $(p<0.001$, Figure 4C).

\section{Protein Synthesis and Degradation}

The genes involved in protein synthesis in our dataset were ribosomal proteins that are involved in the creation of new proteins and lysosomal proteolytic enzymes. Ninety different genes encoding ribosomal proteins are differentially expressed among treatments. Overall, they had higher expression levels in both P-limited and $\mathrm{N}$-limited treatments compared to the replete treatment $(p<0.001$, Figure 4D).

A group of proteolytic enzymes that were annotated by KEGG as lysosomal proteins also had higher expression levels under both P- and N-limitation ( $p<0.05$, Figure 4E). These genes code for 3 aspartyl proteases, 3 cysteine proteases, and 2 serine carboxypeptidases. Six of these eight genes were expressed at higher levels under P-limitation, while seven were expressed at higher levels under $\mathrm{N}$-limitation.

\section{Polyketide Synthase Genes}

There were 15 differentially expressed polyketide synthase (PKS) genes in our dataset. Nine genes had higher expression levels in the P-limited treatment. Among them, transcripts of 5 genes were only detected in the P-limited treatment, while an additional 4 PKS genes were expressed at higher levels under P-limitation compared to the replete treatment. Under $\mathrm{N}$-limitation, 3 genes had higher and 7 genes had lower expression levels compared to the replete condition.

The PKS domains found in the 15 genes included the ketosynthase (KS), ketoreductase (KR), dehydratase (DH), and acyl-carrier-protein (ACP) domains. Of these domains, the KS, $\mathrm{KR}$ and ACP domains are the minimum required domains for PKS synthesis. The gene with the most number of domains, containing a KR domain followed by two ACP domains, had higher expression levels in both nutrient limited treatments. The two genes with KS domains were more highly expressed in the replete treatment compared to both the $\mathrm{N}$-limited and P-limited treatments. One gene with an ACP domain and another with two ACP domains were also more highly expressed in the replete treatment relative to the nutrient-limited treatments. The other genes annotated as PKS genes did not have domain annotations.

\section{Fatty Acid Oxidation and Tricarboxylic Acid (TCA) Cycle Genes}

Many genes in the fatty acid oxidation pathway were expressed at higher levels under both $\mathrm{P}$ - and $\mathrm{N}$-limitation compared to replete condition (Figure 2). Among them were five copies of long-chain acyl-CoA synthetase, two acyl CoA dehydrogenases, and two encoding enoyl-CoA hydratase. Many of the genes involved in the TCA cycle were also similarly expressed at higher levels under both nutrient-limited treatments compared to replete (Figures 2, 4F). They included pyruvate carboxylase, two putative isocitrate dehydrogenase genes, aconitate hydratase fumerase, malate dehydrogenase, 2-oxoglutarate dehydrogenase and succinylcoA synthetase (Table S1). However, citrate synthase was not differentially expressed in any treatments.

\section{Discussion}

\section{Nitrogen Uptake and Metabolism Genes Responded to N Limitation}

Nitrogen is essential for cell maintenance, growth and proliferation, and synthesis of proteins, DNA, RNA and photosynthetic pigments. Under $\mathrm{N}$-limitation, $P$. parvum must meet nitrogen requirements either by increasing the expression of genes used to acquire exogenous nitrogen or by 
TABLE 3 | Expression levels (in FPKM values) and read counts (in numbers of read uniquely aligned read pairs) of additional nitrogen metabolism genes not plotted in Figure 3.

\begin{tabular}{|c|c|c|c|c|}
\hline \multirow[t]{2}{*}{ ID } & \multirow[t]{2}{*}{ Annotation } & \multicolumn{3}{|c|}{ FPKM (read count) } \\
\hline & & Replete & P-limited & N-limited \\
\hline 63323 & Putative urea transporter & $57.3(1159)$ & $13.0(115)$ & $213.2(2589)$ \\
\hline 135159_1 & Putative nitrate transporter & $877.6(3185)$ & $53.6(85)$ & $2527(5505)$ \\
\hline 19338_2 & Carbamoyl-phosphate synthase, large subunit & $10.0(330)$ & $0.1(2)$ & $10.0(198)$ \\
\hline 8693_1 & Carbamoyl-phosphate synthase, large subunit & $16.1(731)$ & $0.3(6)$ & $14.6(400)$ \\
\hline 14637 & Carbamoyl-phosphate synthase, large subunit & $18.9(945)$ & $1.6(36)$ & $12.1(362)$ \\
\hline 19322 & Carbamoyl-phosphate synthase, large subunit & $45.5(1124)$ & $8.6(93)$ & $40.9(607)$ \\
\hline 99020 & Carbamoyl-phosphate synthase, large subunit & $2.3(81)$ & $0.1(0)$ & $2.3(48)$ \\
\hline 19338_2 & Carbamoyl-phosphate synthase, large subunit & $10.0(330)$ & $0.1(2)$ & $10.0(198)$ \\
\hline 57610 & Xanthine dehydrogenase, molybdopterin binding subunit & $13.2(391)$ & $5.7(74)$ & $50.3(896)$ \\
\hline 18242 & Uracil-xanthine permease & $98.0(4083)$ & $25.1(458)$ & $948(23705)$ \\
\hline 55569 & Copper amine oxidase & $6.5(54)$ & $0.6(2)$ & $6.8(34)$ \\
\hline $62477 \_1$ & Urease, alpha subunit & $10.9(285)$ & $9.7(111)$ & $41.5(650)$ \\
\hline 92575 & Argininosuccinate synthase & $39.7(589)$ & $27.3(177)$ & $321.9(2870)$ \\
\hline 63924 & Argininosuccinate lyase & $40.1(679)$ & $10.0(74)$ & 85.9 (873) \\
\hline
\end{tabular}

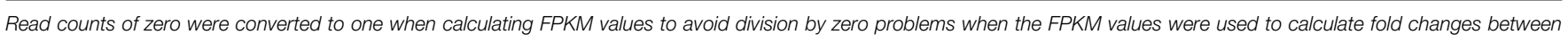
treatments.

repartitioning intracellular pools of nitrogen. Many nitrogen transporters in the assembled transcriptome including those for ammonium, nitrate, nitrite and urea were more highly expressed under N-limitation compared to the nutrient-replete condition (Figures 2, 3). A similar response in nitrogen transporters of $P$. parvum under $\mathrm{N}$-limitation was not observed in a previous study (Beszteri et al., 2012). Expression levels of most of these genes are not very high (in most cases $<1 \%$ of the transcriptome, often lower than $0.1 \%$ ), therefore the apparent discrepancy could be the result of inadequate sequencing depth of the previous study. However, a nitrate transporter and an ammonium transporter were upregulated in a related prymnesiophyte, E. huxleyi, and the pelagophyte, $A$. anophagefferens, under nitrogen stress (Dyhrman et al., 2006; Wurch et al., 2011).

General but non-universal preference among phytoplankton for ammonium uptake and assimilation over nitrate appeared to also apply to P. parvum (Dortch, 1990). Preference for ammonium is energetically favorable as it can be incorporated directly into organic matter via the glutamine-synthetaseglutamate synthase (GS-GOGAT) cycle, while nitrate requires energy for reduction to ammonium before it can be utilized in biological processes (Figure 2). Seven ammonium transporter genes in our assembled transcriptome were upregulated compared to just one nitrate transporter. Diatoms, which tend to readily assimilate nitrate (Sarthou et al., 2005), have also been shown to have more ammonium transporters than nitrate transporters, although the ratio is closer to 2:1 (Hildebrand, 2005).

In addition to increasing gene expression associated with the uptake of exogenous nitrogen, our results indicated an increase in transcription of nitrogen assimilation genes, specifically for the reduction of nitrate to ammonium and for genes in the GSGOGAT cycle. In our study, the cytosolic GSIII genes had higher expression levels under $\mathrm{N}$-limitation, while the chloroplastic GSII did not. The former converts ammonium that is taken up from outside the cell into glutamine while the latter uses the ammonium that is reduced from nitrate within the cell. This may imply that recycled reduced nitrogen from extracellular sources such as proteins might replace nitrate reduction as the main nitrogen source under N-limitation. Conversely, GSIII could be upregulated as a consequence of greater mobilization of intracellular N-pools accompanying degradation of proteins or urea, liberating ammonia that is then reincorporated into other cellular constituents.

\section{Other Nitrogen Metabolism Genes}

We also observed a higher relative expression for one purine transporter under $\mathrm{N}$-limited conditions. These findings are similar to results reported for the prymnesiophyte, E. huxleyi, which was able to grow on purines (Palenik and Henson, 1997) using transporters induced by N-limitation (Shah and Syrett, 1984). Furthermore, at least two important enzymes in the catabolic process of purines, xanthine dehydrogenase and urease had higher relative expression levels under $\mathrm{N}$-limited conditions. Together with a higher relative expression of the active urea transporter DUR3 (Figure 2), our results indicated that $P$. parvum grown under $\mathrm{N}$-limiting conditions exhibited a coordinated response to scavenge $\mathrm{N}$ from organic substrates (Figure 2), contrasting with a previous report that did not observe this response (Beszteri et al., 2012). Similar to the observation by Beszteri et al. (2012), however, a transcript coding for a copper-amine oxidase had lower expression levels in the P-limited treatment compared to the replete condition (CuAO in Figure 2). CuAO has a $\alpha$-helix at the $\mathrm{N}$-terminal, suggesting that it might correspond to the same membranebound enzyme described in $P$. parvum that oxidizes primary 


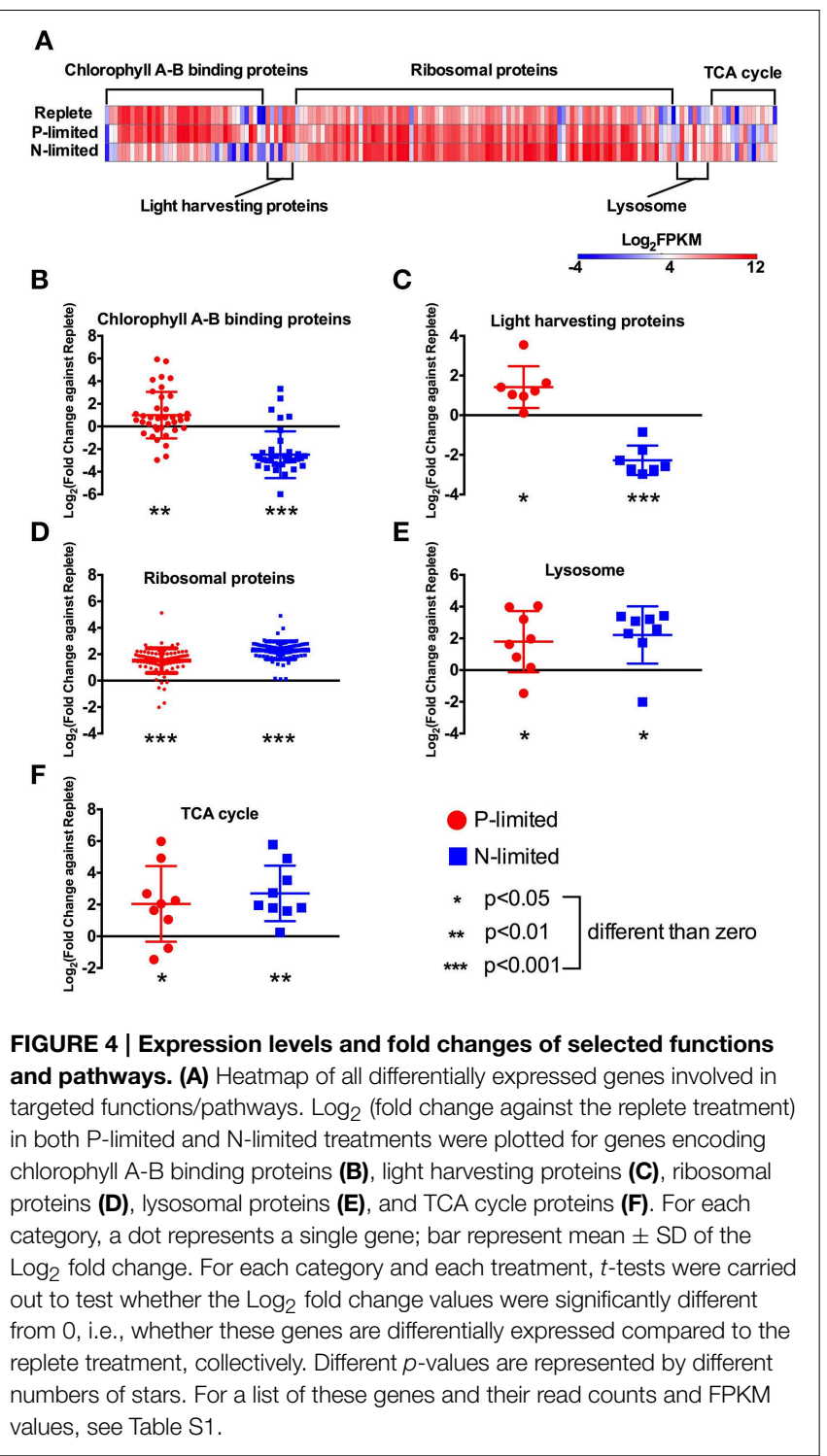

amines to produce extracellular ammonium (Palenik and Morel, 1991). This activity combined with the uptake of ammonium suggests that this enzyme plays a role in cell nutrition. The lower relative expression of this enzyme is thus in line with the lower relative expression of ammonium transporters in the P-limited treatment.

\section{Phosphate Transporters Responded to P Limitation}

The most highly expressed gene under P-limitation was a phosphate transporter belonging to the Pho4 superfamily of phosphate permeases. The Pho4 superfamily includes both highand low-affinity phosphate transporters. In yeast, the lowaffinity phosphate transport system, thought to be constitutively expressed, satisfies the cellular requirement for inorganic phosphate when external levels of phosphate are high or sufficient. In contrast, the high-affinity phosphate transport system is used when ambient phosphate levels are limiting to growth (Persson et al., 2003). In other microbial eukaryotes, genes with homology to pho4 have been found in species from different phylogenetic groups including chlorophytes, Tetraselmis chui, and Dunialiella viridis (Chung et al., 2003; Li et al., 2006), several prasinophytes (Monier et al., 2012), the pelagophyte $A$. anophagefferens (Wurch et al., 2011), and the prymnesiophyte E. huxleyi (Dyhrman et al., 2006). Experimental evidence and the phylogenetic placements of these pho4 genes suggest that they are all high-affinity transporters, and that Pdepletion induces upregulation of these genes (Wykoff et al., 2007).

In addition to the putative pho4 gene, other transporters were detected in this study that were annotated as sodium-dependent inorganic phosphate transporters. These transporters couple the uptake of inorganic phosphorus to the ionic gradient formed by the movement of $\mathrm{Na}^{+}$(Persson et al., 2003). While three of these transporters were upregulated under P-limitation, one was downregulated compared to the replete condition. We suggest that differential regulation of these genes in $P$. parvum with putatively similar function may be a result of their different affinities for transporting inorganic phosphorus. Differential upregulation in $P$. parvum of the two phosphate permeases and two acid phosphatases under $\mathrm{P}$ limitation was described previously (Beszteri et al., 2012). In this study, one of each type was upregulated indicating that there could be different phosphorus acquisition systems depending on the nutrient status of the cell. Taken together, the two different phosphate transporter families indicate different cellular responses to acquire more phosphorus when the nutrient is limiting to growth of P. parvum.

\section{Photosynthesis Responded Differently to $\mathbf{N}$ and $\mathbf{P}$ Limitation}

Genes associated with photosynthesis in $P$. parvum in our study responded differently to $\mathrm{N}$ and $\mathrm{P}$ limitations. Under $\mathrm{P}$ limitation, higher expression levels of photosynthesis genes were observed relative to the $\mathrm{N}$-limited treatment (Figures 4B,C). Expression levels of genes related to photosynthesis were higher under P-limitation possibly to compensate for a reduction in photosynthesis efficiency $\left(\mathrm{F}_{\mathrm{v}} / \mathrm{F}_{\mathrm{m}}\right)$, which has been observed for some algae under phosphorus limitation (Shen and Song, 2007). Alternatively, we speculate that the relative upregulation of photosynthesis genes under phosphorus limitation may provide energy necessary to fuel increased cellular reorganization and/or toxin synthesis under P-limited conditions.

Maintenance of the photosynthetic apparatus is thought to require much higher levels of $\mathrm{N}$ than $\mathrm{P}$ because of the large amounts of N-rich chlorophylls. This may explain why $\mathrm{N}$-limitation had a greater negative effect on the expression levels of photosynthesis genes than P-limitation, a situation observed for several other photosynthetic microorganisms. In the unicellular cyanobacterium Synechococcus spp., components of the cell's photosynthetic machinery such as chlorophyll, phycocyanin, and phycobilisomes responded differently to $\mathrm{N}$ and P-deprivation, generally with a greater negative effect observed under nitrogen limitation (Collier and Grossman, 1992). Similarly, a decline in the number of photosystem II 
reaction centers in the green alga, Chlamydomonas sp. was found to be greater under $\mathrm{N}$-deprivation compared to $\mathrm{P}$ deprivation (Grossman, 2000). The coccolithophore, E. huxleyi, also yielded results similar to our study, wherein five putative fucoxanthin chlorophyll a-b binding protein genes were found to be highly upregulated under P-limitation and downregulated under N-limitation (Dyhrman et al., 2006). Genes involved in photosynthesis were also downregulated in Chlamydomonas reinhardtii under N-limitation (Miller et al., 2010).

\section{Genes Involved in Protein Production and Turnover Responded to $\mathbf{N}$ - and P-limitation}

Our results indicate that $P$. parvum increased the expression of genes involved in both protein synthesis and degradation under both $\mathrm{N}$ - and P- limitation (Figures 4D,E). Similarly, multiple rRNA transcripts were shown to be upregulated under P-limitation in E. huxleyi (Dyhrman et al., 2006), although this is not a universal transcriptional response, as observed for the diatom T. pseudonana (Dyhrman et al., 2012). The higher expression levels of ribosomal genes was somewhat surprising under N-limitation, as protein synthesis might be hampered due to large requirements of $\mathrm{N}$. However, the higher expression levels of lysosome-related genes (Figure 4E) implies a higher protein degradation rate, which might provide the amino acids required for new protein synthesis. Our results suggest that there is an overall response for protein and amino acid recycling in $P$. parvum under nutrient limitation. Under these conditions, we speculate that large amounts of proteins might need to be recycled to make other proteins that directly address nutrient deficiencies, such as ammonium and phosphate transporters, or cellular reorganization associated with the cessation of population growth in stationary phase.

\section{Polyketide Synthase (PKS) Genes Respond to Nutrient Limitation}

PKS compounds have been implicated as the basis for toxins in many dinoflagellates (Kellmann et al., 2010) and are thought to be responsible for some if not all of the toxins present in prymnesiophytes (Freitag et al., 2011). Two P. parvum toxins have been isolated to date, prymnesin 1 and prymnesin2 (Igarashi et al., 1999; Manning and La Claire, 2010) although other yet uncharacterized toxins may be present (Cichewicz and Hambright, 2010). Prymnesins are polyether compounds similar to other algal toxins such as brevitoxin and okadaic acid, which are produced by Type I PKS genes. PKS genes have been found in the transcriptome of $P$. parvum and other related prymnesiophytes, with the ketosyntase (KS) domain of the PKS genes clustered into two separate clades, one comprising prymnesiophyte-specific sequences and one apparently of diverse bacterial and protistan origin (Koid et al., 2014).

Our dataset contained many different PKS genes that exhibited different expression patterns. However, 9 of the 15 genes had higher expression levels under P-limitation, consistent with previous observations of increased toxicity under Plimitation (Graneli and Johansson, 2003; Uronen et al., 2005). It is not yet known which of the PKS genes participate in toxin production, and it is also possible that some PKS genes participate in the synthesis of different toxins (Manning and La Claire, 2010). However, the PKS genes that responded positively to nutrient limitation in the present study provide targets for further study focused on identifying genes and pathways involved in toxin production in P. parvum. Under P-limitation, increased toxin production and release may help $P$. parvum obtain more extracellular phosphorus from lysed cells of other organisms (Graneli and Salomon, 2010). The higher expression of some PKS genes in our study is consistent with the suggestion that P-limited cells have higher toxicity than nutrient-replete cells, which might be part of a coordinated physiological response to P-limitation. We hypothesize that the upregulation of photosynthetic genes under $\mathrm{P}$ limitation described above may provide cells with the energy necessary for toxin production.

\section{Fatty Acid Oxidation and the TCA Cycle}

Fatty acid breakdown involves multiple cycles of $\beta$-oxidationdepending on the length of the fatty acid-and results in acetyl-CoA and $\mathrm{NADH}$ and $\mathrm{FADH}_{2}$. We observed an increase in the expression levels of many genes involved in fatty acid (FA) oxidation in response to both types of nutrient limitation (Figure 2). This was an unexpected result based on observations that phytoplankton such as the green alga, Chlamydomonas, are thought not to synthesize fatty acids under nutrient limitation (Moseley et al., 2006). While many of these enzymes function bidirectionally, acyl-CoA dehydrogenase is unidirectional. Therefore, its higher expression level under Pand $\mathrm{N}$-limitation might indicate that other enzymes are also catalyzing reactions that result in an increase in acetyl-CoA. Acetyl-CoA can feed into a number of different downstream pathways, one of which is the TCA cycle, while another is PKS synthesis (Dewick, 2002). The expression levels of PKS genes rose under P-limitation, as noted above. TCA cycle genes had higher expression levels under both $\mathrm{P}$ and $\mathrm{N}$-limitation (Figure 4F), implying one possible use of the additional acetylCoA might be energy production through the TCA cycle. The increase in expression levels of TCA cycles could also have many other implications such as possible increased production of 2-oxoglutarate for the GS/GOGAT cycle.

\section{Conclusions}

P. parvum exhibited two types of responses under N- and Plimitation: responses that were specific to either $\mathrm{P}$ or $\mathrm{N}$ limitation, and a general response common to both nutrient stress conditions. P-limitation resulted in the increased expression of phosphate transporters, photosynthesis genes and polyketide synthase genes. Toxin synthesis might be related to the acquisition of extracellular $P$ when that nutrient is limiting, while the relative upregulation of photosynthesis genes might provide the energy necessary to fuel the increased cellular activity. $\mathrm{N}$ and P-limitation both resulted in an increase in genes involved in protein synthesis and turnover, fatty acid oxidation and the TCA cycle. Under $\mathrm{N}$ limitation, cells upregulated genes associated with $\mathrm{N}$ assimilation including a myriad of different transporters and nitrogen-related pathways. This robust cellular response included the processing or reallocation of intracellular nitrogen, 
such as seen in the de novo purine biosynthesis pathway. Taken together, the results of this study highlight the ability of $P$. parvum to mount a coordinated and varied cellular and physiological response to nutrient limitation.

\section{Acknowledgments}

This research was funded in part by the Gordon and Betty Moore Foundation through Grant \#3299 to DC and KH. The sequencing was funded by the Gordon and Betty Moore Foundation through Grant \#2637 to the National Center for

\section{References}

Aguiar, R., and Kugrens, P. (2000). New and rare chrysophytes from Wyoming and Colorado lakes. J. Phycol. 36, 1-2. doi: 10.1046/j.1529-8817.1999.00001-3.x

Allen, A. E., Dupont, C. L., Oborník, M., Horák, A., Nunes-Nesi, A., McCrow, J. P., et al. (2011). Evolution and metabolic significance of the urea cycle in photosynthetic diatoms. Nature 473, 203-207. doi: 10.1038/nature10074

Altschul, S. F., Gish, W., Miller, W., Myers, E. W., and Lipman, D. J. (1990). Basic local alignment search tool. J. Mol.. Biol. 215, 403-410. doi: 10.1016/S00222836(05)80360-2

Aure, J., and Rey, F. (1992). Oceanographic conditions in the sandsfjord system, western Norway, after a bloom of the toxic prymnesiophyte Prymnesium parvum Carter in August 1990. Sarsia 76, 247-254.

Bachmann, B. O., and Ravel, J. (2009). Chapter 8. Methods for in silico prediction of microbial polyketide and nonribosomal peptide biosynthetic pathways from DNA sequence data. Methods Enzymol. 458, 181-217. doi: 10.1016/s00766879(09)04808-3

Baker, J. W., Grover, J. P., Ramachandrannair, R., Black, C., Valenti, T. W., Brooks, B. W., et al. (2009). Growth at the edge of the niche: an experimental study of the harmful alga Prymnesium parvum. Limnol. Oceanogr. 54, 1679-1687. doi: 10.4319/lo.2009.54.5.1679

Benjamini, Y., and Hochberg, Y. (1995). Controlling the false discovery rate: a practical and powerful approach to multiple testing. J. R. Stat. Soc. Ser. B 57, 289-300.

Beszteri, S., Yang, I., Jaeckisch, N., Tillmann, U., Frickenhaus, S., Glöckner, G., et al. (2012). Transcriptomic response of the toxic prymnesiophyte Prymnesium parvum (N. Carter) to phosphorus and nitrogen starvation. Harmful Algae 18, 1-15. doi: 10.1016/j.hal.2012.03.003

Burkholder, J. M., Glibert, P. M., and Skelton, H. M. (2008). Mixotrophy, a major mode of nutrition for harmful algal species in eutrophic waters. Harmful Algae 8, 77-93. doi: 10.1016/j.hal.2008.08.010

Chung, C. C., Hwang, S. P., and Chang, J. (2003). Identification of a high-affinity phosphate transporter gene in a prasinophyte alga, Tetraselmis chui, and its expression under nutrient limitation. Appl. Environ. Microbiol. 69, 754-759. doi: 10.1128/AEM.69.2.754-759.2003

Cichewicz, R. H., and Hambright, K. D. (2010). A revised amino group pK(a) for prymnesins does not provide decisive evidence for a $\mathrm{pH}$-dependent mechanism of Prymnesium parvum's toxicity. Toxicon 55, 1035-1037. doi: 10.1016/j.toxicon.2010.02.002

Collier, J. L., and Grossman, A. R. (1992). Chlorosis induced by nutrient deprivation in Synechococcus sp strain PCC-7942: not all bleaching is the same. J. Bacteriol. 174, 4718-4726.

Conesa, A., Götz, S., García-Gómez, J. M., Terol, J., Talón, M., and Robles, M. (2005). Blast2GO: a universal tool for annotation, visualization and analysis in functional genomics research. Bioinformatics 21, 3674-3676. doi: 10.1093/bioinformatics/bti610

Dewick, P. M. (2002). Medicinal Natural Products: A Biosynthetic Approach, 2nd Edn. Chichester: John Wiley \& Sons, Ltd.

Dick, C. F., Dos-Santos, A. L., and Meyer-Fernandes, J. R. (2014). Inorganic phosphate uptake in unicellular eukaryotes. Biochim. Biophys. Acta 1840, 2123-2127. doi: 10.1016/j.bbagen.2014.03.014
Genome Resources. We would like to thank K. David Hambright (University of Oklahoma) for making the culture of Prymnesium parvum available, Adriane Jones for early stage ideas, and John Heidelberg for discussion of bioinformatics analysis procedures.

\section{Supplementary Material}

The Supplementary Material for this article can be found online at: http://journal.frontiersin.org/article/10.3389/fmicb. 2015.00631

Dortch, Q. (1990). The interaction between ammonium and nitrate uptake in phytoplankton. Mar. Ecol. Prog. Ser. 61, 183-201. doi: 10.3354/meps061183

Dyhrman, S. T., Haley, S. T., Birkeland, S. R., Wurch, L. L., Cipriano, M. J., and McArthur, A. G. (2006). Long serial analysis of gene expression for gene discovery and transcriptome profiling in the widespread marine coccolithophore Emiliania huxleyi. Appl. Environ. Microbiol. 72, 252-260. doi: 10.1128/AEM.72.1.252-260.2006

Dyhrman, S. T., Jenkins, B. D., Rynearson, T. A., Saito, M. A., Mercier, M. L., Alexander, H., et al. (2012). The transcriptome and proteome of the diatom Thalassiosira pseudonana reveal a diverse phosphorus stress response. PLoS ONE 7:e33768. doi: 10.1371/journal.pone.0033768

Edvardsen, B., and Paasche, E. (1998). "Bloom dynamics and physiology of Prymnesium and Chrysochromulina," in Physiological Ecology of Harmful Algal Blooms, eds D. M. Anderson, A. D. Cembella, and G. M. Hallegraeff (Berlin; Heidelberg; New York: Springer), 193-208.

Finn, R. D., Mistry, J., Tate, J., Coggill, P., Heger, A., Pollington, J. E., et al. (2010). The Pfam protein families database. Nucleic Acids Res. 38, D211-D222. doi: 10.1093/nar/gkp985

Freitag, M., Beszteri, S., Vogel, H., and John, U. (2011). Effects of physiological shock treatments on toxicity and polyketide synthase gene expression in Prymnesium parvum (Prymnesiophyceae). Eur. J. Phycol. 46, 193-201. doi: 10.1080/09670262.2011.591438

Graneli, E., and Johansson, N. (2003). Increase in the production of allelopathic substances by Prymnesium parvum cells grown under $\mathrm{N}$ - or P-deficient conditions. Harmful Algae 2, 135-145. doi: 10.1016/S1568-9883(03)00006-4

Graneli, E., and Salomon, P. S. (2010). Factors influencing allelopathy and toxicity in Prymnesium parvum. J. Am. Water Resour. Ass. 46, 108-120. doi: 10.1111/j.1752-1688.2009.00395.x

Grossman, A. (2000). Acclimation of Chlamydomonas reinhardtii to its nutrient environment. Protist 151, 201-224. doi: 10.1078/1434-4610-00020

Guillard, R. R. L., and Hargraves, P. E. (1993). Stichochrysis immobilis is a diatom, not a chrysophyte. Phycologia 32, 234-236. doi: 10.2216/i0031-8884-32-3234.1

Haft, D. H., Loftus, B. J., Richardson, D. L., Yang, F., Eisen, J. A., Paulsen, I. T., et al. (2001). TIGRFAMs: a protein family resource for the functional identification of proteins. Nucleic Acids Res. 29, 41-43. doi: 10.1093/nar/29.1.41

Hambright, K. D., Zamor, R. M., Easton, J. D., Glenn, K. L., Remmel, E. J., and Easton, A. C. (2010). Temporal and spatial variability of an invasive toxigenic protist in a North American subtropical reservoir. Harmful Algae 9, 568-577. doi: 10.1016/j.hal.2010.04.006

Hargraves, P. E., and Maranda, L. (2002). Potentially toxic or harmful microalgae from the northeast coast. Northeast Nat. 9, 81-120. doi: 10.1656/10926194(2002)009[0081:PTOHMF]2.0.CO;2

Hildebrand, M. (2005). Cloning and functional characterization of ammonium transporters from the marine diatom Cylindrotheca fusiformis (Bacillariophyceae). J. Phycol. 41, 105-113. doi: 10.1111/j.15298817.2005.04108.x

Huang, X., and Madan, A. (1999). CAP3: a DNA sequence assembly program. Genome Res. 9, 868-677. doi: 10.1101/gr.9.9.868

Igarashi, T., Satake, M., and Yasumoto, T. (1999). Structures and partial stereochemical assignments for prymnesin-1 and prymnesin-2: potent 
hemolytic and ichthyotoxic glycosides isolated from the red tide alga Prymnesium parvum. J. Am. Chem. Soc. 121, 8499-8511. doi: 10.1021/ja99 $1740 \mathrm{e}$

Iseli, C., Jongeneel, C. V., and Bucher, P. (1999). ESTScan: a program for detecting, evaluating, and reconstructing potential coding regions in EST sequences. Proc. Int. Conf. Intell. Syst. Mol. Biol. 1, 138-148.

Kaartvedt, S., Johnsen, T. M., Aksnes, D. L., Lie, U., and Svendsen, H. (1991). Occurrence of the toxic phytoflagellate Prymnesium parvum and associated fish mortality in a Norwegian fjord system. Can. J. Fish. Aquat. Sci. 48, 2316-2323. doi: 10.1139/f91-272

Keeling, P. J., Burki, F., Wilcox, H. M., Allam, B., Allen, E. E., Amaral-Zettler, L. A., et al. (2014). The Marine Microbial Eukaryote Transcriptome Sequencing Project (MMETSP): illuminating the functional diversity of eukaryotic life in the oceans through transcriptome sequencing. PLoS Biol. 12:e1001889. doi: 10.1371/journal.pbio.1001889

Kellmann, R., Stüken, A., Orr, R. J., Svendsen, H. M., and Jakobsen, K. S. (2010). Biosynthesis and molecular genetics of polyketides in marine dinoflagellates. Mar. Drugs 8, 1011-1048. doi: 10.3390/md8041011

Koid, A. E., Liu, Z. F., Terrado, R., Jones, A. C., Caron, D. A., and Heidelberg, K. B. (2014). Comparative transcriptome analysis of four prymnesiophyte algae. PLoS ONE 9:e97801. doi: 10.1371/journal.pone.0097801

La Claire, J. W. (2006). Analysis of expressed sequence tags from the harmful alga, Prymnesium parvum (Prymnesiophyceae, Haptophyta). Mar. Biotechnol. 8, 534-546. doi: 10.1007/s10126-005-5182-2

Li, H., and Durbin, R. (2009). Fast and accurate short read alignment with Burrows-Wheeler transform. Bioinformatics 25, 1754-1760. doi: 10.1093/bioinformatics/btp324

Li, Q., Gao, X., Sun, Y., Zhang, Q., Song, R., and Xu, Z. (2006). Isolation and characterization of a sodium-dependent phosphate transporter gene in Dunaliella viridis. Biochem. Biophys. Res. Commun. 340, 95-104. doi: 10.1016/j.bbrc.2005.11.144

Li, W., and Godzik, A. (2006). Cd-hit: a fast program for clustering and comparing large sets of protein or nucleotide sequences. Bioinformatics 22, 1658-1659. doi: 10.1093/bioinformatics/btl158

Lindholm, T., Ohman, P., Kurki-Helasmo, K., Kincaid, B., and Meriluoto, J. (1999). Toxic algae and fish mortality in a brackish-water lake in angstrom land, SW Finland. Hydrobiologia 397, 109-120. doi: 10.1023/A:10036677 28458

Liu, Z., Jones, A. C., Campbell, V., Hambright, K. D., Heidelberg, K. B., and Caron, D. A. (2015). Gene expression in the mixotrophic prymnesiophyte, Prymnesium parvum, responds to prey availability. Front. Microbiol. 6:319. doi: 10.3389/fmicb.2015.00319

Luo, R., Liu, B., Xie, Y., Li, Z., Huang, W., Yuan, J., et al. (2012). SOAPdenovo2: an empirically improved memory-efficient short-read de novo assembler. Gigascience 1:18. doi: 10.1186/2047-217X-1-18

Manning, S. R., and La Claire, J. W. (2010). Prymnesins: toxic metabolites of the golden alga, Prymnesium parvum Carter (Haptophyta). Mar. Drugs 8, 678-704. doi: $10.3390 / \mathrm{md} 8030678$

Manning, S. R., and La Claire, J. W. (2013). Isolation of polyketides from Prymnesium parvum (Haptophyta) and their detection by liquid chromatography/mass spectrometry metabolic fingerprint analysis. Anal. Biochem. 442, 189-195. doi: 10.1016/j.ab.2013.07.034

McGettigan, P. A. (2013). Transcriptomics in the RNA-seq era. Curr. Opin. Chem. Biol. 17, 4-11. doi: 10.1016/j.cbpa.2012.12.008

Miller, R., Wu, G., Deshpande, R. R., Vieler, A., Gärtner, K., Li, X., et al. (2010). Changes in transcript abundance in Chlamydomonas reinhardtii following nitrogen deprivation predict diversion of metabolism. Plant Physiol. 154, 1737-1752. doi: 10.1104/pp.110.165159

Mitra, A., and Flynn, K. J. (2010). Modelling mixotrophy in harmful algal blooms: more or less the sum of the parts? J. Mar. Syst. 83, 158-169. doi: 10.1016/j.jmarsys.2010.04.006

Moestrup, Ø. (1994). "Economic aspects: 'blooms', nuisance species and toxins," in The Haptophyte Algae. Systematics Association Special, Vol. 51, eds J. C. Green and B. S. C. Leadbeater (Oxford: Clarendon Press), 265-285.

Monier, A., Welsh, R. M., Gentemann, C., Weinstock, G., Sodergren, E., Armbrust, E. V., et al. (2012). Phosphate transporters in marine phytoplankton and their viruses: cross-domain commonalities in viral-host gene exchanges. Environ. Microbiol. 14, 162-176. doi: 10.1111/j.1462-2920.2011.02576.x
Moriya, Y., Itoh, M., Okuda, S., Yoshizawa, A., and Kanehisa, M. (2007). KAAS: an automatic genome annotation and pathway reconstruction server. Nucleic. Acids. Res. 35, W182-W185. doi: 10.1093/nar/gkm321

Moseley, J. L., Chang, C. W., and Grossman, A. R. (2006). Genome-based approaches to understanding phosphorus deprivation responses and PSR1 control in Chlamydomonas reinhardtii. Eukaryotic Cell. 5, 26-44. doi: 10.1128/EC.5.1.26-44.2006

Moustafa, A., Evans, A. N., Kulis, D. M., Hackett, J. D., Erdner, D. L., Anderson, D. M., et al. (2010). Transcriptome profiling of a toxic dinoflagellate reveals a gene-rich protist and a potential impact on gene expression due to bacterial presence. PLoS ONE 5:e9688. doi: 10.1371/journal.pone.0009688

Palenik, B., and Henson, S. E. (1997). The use of amides and other organic nitrogen sources by the phytoplankton Emiliania huxleyi. Limnol. Oceanogr. 42, 1544-1551. doi: 10.4319/lo.1997.42.7.1544

Palenik, B., and Morel, F. M. M. (1991). Amine oxidases of marine phytoplankton. Appl. Environ. Microbiol. 57, 2440-2443.

Park, S., Jung, G., Hwang, Y. S., and Jin, E. (2010). Dynamic response of the transcriptome of a psychrophilic diatom, Chaetoceros neogracile, to high irradiance. Planta 231, 349-360. doi: 10.1007/s00425-009-1044-x

Persson, B. L., Lagerstedt, J. O., Pratt, J. R., Pattison-Granberg, J., Lundh, K., Shokrollahzadeh, S., et al. (2003). Regulation of phosphate acquisition in Saccharomyces cerevisiae. Curr. Genet. 43, 225-244. doi: 10.1007/s00294-0030400-9

Price, M. N., Dehal, P. S., and Arkin, A. P. (2010). FastTree 2-approximately maximum-likelihood trees for large alignments. PLoS ONE 5:e9490. doi: 10.1371/journal.pone.0009490

Quast, C., Pruesse, E., Yilmaz, P., Gerken, J., Schweer, T., Yarza, P., et al. (2013). The SILVA ribosomal RNA gene database project: improved data processing and web-based tools. Nucleic Acids Res. 41, D590-D596. doi: 10.1093/nar/ gks1219

Read, B. A., Kegel, J., Klute, M. J., Kuo, A., Lefebvre, S. C., Maumus, F., et al. (2013). Pan genome of the phytoplankton Emiliania underpins its global distribution. Nature 499, 209-213. doi: 10.1038/nature12221

Robertson, G., Schein, J., Chiu, R., Corbett, R., Field, M., Jackman, S. D., et al. (2010). De novo assembly and analysis of RNA-seq data. Nat. Methods 7, 909-912. doi: 10.1038/nmeth.1517

Robinson, M. D., McCarthy, D. J., and Smyth, G. K. (2010). edgeR: a Bioconductor package for differential expression analysis of digital gene expression data. Bioinformatics 26, 139-140. doi: 10.1093/bioinformatics/btp616

Sanders, R. W. (2011). Alternative nutritional strategies in protists: symposium introduction and a review of freshwater protists that combine photosynthesis and heterotrophy. J. Eukaryot. Microbiol. 58, 181-184. doi: 10.1111/j.15507408.2011.00543.x

Sarthou, G., Timmermans, K. R., Blain, S., and Treguer, P. (2005). Growth physiology and fate of diatoms in the ocean: a review. J. Sea Res. 53, 25-42. doi: 10.1016/j.seares.2004.01.007

Shah, N., and Syrett, P. J. (1984). The uptake of guanine and hypoxanthine by marine microalgae. J. Mar. Biol. Assoc. U.K. 64, 545-556. doi: $10.1017 / \mathrm{S} 002531540003023 \mathrm{X}$

Shen, H., and Song, L. R. (2007). Comparative studies on physiological responses to phosphorus in two phenotypes of bloom-forming Microcystis. Hydrobiologia 592, 475-486. doi: 10.1007/s10750-007-0794-3

Shilo, M. (1971). "Toxins of chrysophyceae," in Microbial Toxins, eds S. Kadis, A. Ciegler, and S. J. Ajl (New York, NY: Academic Press), 67-103.

Shilo, M. (1981). "The toxic principles of Prymnesium parvum," in The Water Environment, ed W. Carmichael (New York, NY: Springer), 37-47.

Simpson, J. T., Wong, K., Jackman, S. D., Schein, J. E., Jones, S. J., and Birol, I. (2009). ABySS: a parallel assembler for short read sequence data. Genome Res. 19, 1117-1123. doi: 10.1101/gr.089532.108

Stoecker, D. K. (1998). Conceptual models of mixotrophy in planktonic protists and some ecological and evolutionary implications. Eur. J. Protistol. 34, 281-290. doi: 10.1016/S0932-4739(98)80055-2

Sunda, W. G., Graneli, E., and Gobler, C. J. (2006). Positive feedback and the development and persistence of ecosystem disruptive algal blooms. J. Phycol. 42, 963-974. doi: 10.1111/j.1529-8817.2006.00261.x

Talavera, G., and Castresana, J. (2007). Improvement of phylogenies after removing divergent and ambiguously aligned blocks from protein sequence alignments. Syst. Biol. 56, 564-577. doi: 10.1080/10635150701472164 
Terrado, R., Monier, A., Edgar, R., and Lovejoy, C. (2015). Diversity of nitrogen assimilation pathways among microbial photosynthetic eukaryotes. J. Phycol. 51, 490-506. doi: 10.1111/jpy.12292

Tillmann, U. (2003). Kill and eat your predator: a winning strategy of the planktonic flagellate Prymnesium parvum. Aquat. Microb. Ecol. 32, 73-84. doi: 10.3354/ame032073

Uronen, P., Lehtinen, S., Legrand, C., Kuuppo, P., and Tamminen, T. (2005). Haemolytic activity and allelopathy of the haptophyte Prymnesium parvum in nutrient-limited and balanced growth conditions. Mar. Ecol. Prog. Ser. 299, 137-148. doi: 10.3354/meps299137

von Dassow, P., Ogata, H., Probert, I., Wincker, P., da Silva, C., Audic, S., et al. (2009). Transcriptome analysis of functional differentiation between haploid and diploid cells of Emiliania huxleyi, a globally significant photosynthetic calcifying cell. Genome Biol. 10:R114. doi: 10.1186/gb-2009-1010-r114

Watson, S. (2001). Literature Review of the Microalga Prymnesium Parvum and its Associated Toxicity. Texas Parks and Wildlife Department, Report T3200-1158 (2001, August).

Wurch, L. L., Haley, S. T., Orchard, E. D., Gobler, C. J., and Dyhrman, S. T. (2011). Nutrient-regulated transcriptional responses in the brown tide-forming alga Aureococcus anophagefferens. Environ. Microbiol. 13, 468-481. doi: 10.1111/j.1462-2920.2010.
Wykoff, D. D., Rizvi, A. H., Raser, J. M., Margolin, B., and O’Shea, E. K. (2007). Positive feedback regulates switching of phosphate transporters in S. cerevisiae. Mol. Cell 27, 1005-1013. doi: 10.1016/j.molcel.2007.07.022

Yariv, J., and Hestrin, S. (1961). Toxicity of the extracellular phase of Prymnesium parvum cultures. J. Gen. Microbiol. 24, 165-175. doi: 10.1099/00221287-242-165

Zhang, Z., and Wood, W. I. (2003). A profile hidden Markov model for signal peptides generated by HMMER. Bioinformatics 19, 307-308. doi: 10.1093/bioinformatics/19.2.307

Conflict of Interest Statement: The Associate Editor Senjie Lin declares that, despite having collaborated with author David A. Caron, the review process was handled objectively and no conflict of interest exists. The authors declare that the research was conducted in the absence of any commercial or financial relationships that could be construed as a potential conflict of interest.

Copyright (c) 2015 Liu, Koid, Terrado, Campbell, Caron and Heidelberg. This is an open-access article distributed under the terms of the Creative Commons Attribution License (CC BY). The use, distribution or reproduction in other forums is permitted, provided the original author(s) or licensor are credited and that the original publication in this journal is cited, in accordance with accepted academic practice. No use, distribution or reproduction is permitted which does not comply with these terms. 